\title{
INULIN AND ENDOGENOUS AMINO ACID RENAL CLEARANCES IN CYSTINURIA: EVIDENCE FOR TUBULAR SECRETION*
}

\author{
By GEORGE W. FRIMPTER, $†$ MELVIN HORWITH, EUGENE FURTH, \\ ROBERT E. FELLOWS $\ddagger$ AND DAVID D. THOMPSON WITH THE \\ TECH NICAL ASSISTANCE OF AUDREY BASS AND \\ NAOMI SCHECHTER
}

(From the Department of Medicine, Cornell University Medical College, New York, N. Y.)

(Submitted for publication July 17, 1961 ; accepted October 9, 1961)

Cystinuria is manifested by cystine calculi and high urinary excretion of cystine (2), lysine, arginine (3), and ornithine (4). Abnormally low plasma levels have been established for cystine $(5,6)$, lysine $(7)$, arginine, and ornithine $(5,8)$. Several investigators have previously demonstrated increased renal clearances for cystine, lysine, arginine, and ornithine (7-11).

These four amino acids each have two amino groups separated by 4 to 6 carbon atoms. This led Dent and Rose to suggest that a common enzymatic mechanism for their renal tubular reabsorption is missing in cystinuria (11). Further support for this hypothesis was provided by the demonstration that intravenous infusion of lysine produced increased excretion of cystine and arginine in nomal individuals but not in those with cystinuria $(7,10)$.

In addition to the four amino acids previously mentioned, studies in this laboratory have recently demonstrated that significant amounts of the asymmetrical disulfide of L-cysteine and L-homocysteine were excreted by all of 10 patients with classical cystinuria (12). This substance was recorded by Stein as a peak in the isoleucine area of the ion-exchange chromatogram (4). $\mathrm{He}$ determined the relative molar excretion of cystine, arginine, lysine, and ornithine in the urine of five patients with cystinuria, without reference, however, to plasma concentrations or renal func-

* This study was supported in part by Grant no. H-8418 of the National Institutes of Health, U. S. Public Health Service; by a grant from the Kidney Disease Foundation of New York; and by a grant from The National Foundation, Inc. Part of this work has appeared in abstract form (1).

† Senior Research Fellow, New York Heart Association.

$¥$ Present address: Department of Medicine, Royal Victoria Hospital, Montreal, Canada. tion (4). A more accurate description of the renal tubular defect in cystinuria would be provided by the measurement of renal clearances of cystine, lysine, arginine, and ornithine in specimens of plasma and urine from the same clearance period, by a single accurate sensitive technique that would permit measurement of the amino acids at their endogenous concentrations. The present study emphasizes column chromatography on ion-exchange resins with the use of the automatic recording apparatus of Spackman, Stein and Moore (13) to relate amino acid clearances to the inulin clearance. Unexpected data were obtained in one patient and these are discussed in detail.

\section{METHODS}

Patients. Four patients with classical cystinuria were studied. None of these patients had a family history of cystinuria, and no increased amino acid excretion was found in those relatives whose urine was examined by paper or column chromatography, or both. Because large amounts of amino acids were excreted by these patients, it seems probable that they are homozygous for the cystinuric trait. All had experienced renal calculi in the past, and all had had stones removed operatively. All patients were studied on a metabolic ward in the New York Hospital. At the time of the study the patients had no clinical or roentgenological evidence of calculi and none had urinary tract infection as determined by examination of the urinary sediment and culture for bacteria. All patients, except F.C., had been maintained for several months on a diet calculated to contain a restricted amount of methionine per day. The patients were on a constant low methionine diet in the hospital for 3 days prior to the clearance study. Alkali had been administered in the past, but was discontinued for 3 days prior to the study. Fluid intake varied with the conditions of the study. In those patients in whom the clearance study was begun with a low urine flow, fluid intake was restricted after 9 p.m. on the evening before the study. Clinical data are summarized in Table I.

Clearance procedures. Clearances of inulin and amino acids were performed in the fasting state. Adequate 
TABLE I

Abbreviated clinical data on four patients studied

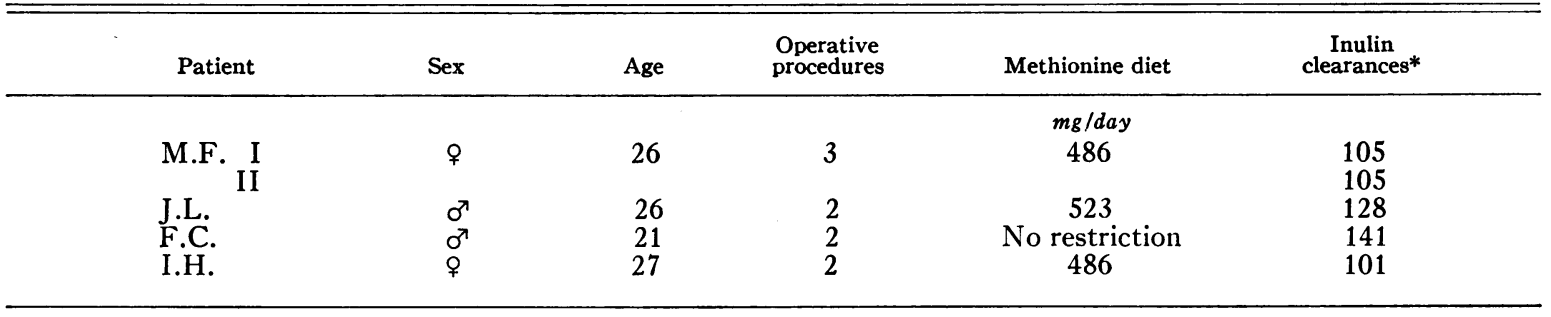

* Per $1.73 \mathrm{~m}^{2}$ body surface area.

urine collections were assured by the use of a multi-hole indwelling catheter and air washout. In addition, urine flow was augmented by administering an oral water load. In some studies urine flow was increased in a stepwise fashion in order to examine the effects of urine flow on the amino acid clearances. In other studies a high rate of urine flow was sustained throughout the urine collection periods. After a priming dose, inulin in isotonic saline was administered into an antecubital vein with a constant infusion pump. Blood specimens were obtained at the midpoint of the urine collection periods. To avoid stasis and hemolysis, $50-\mathrm{ml}$ aliquots of blood were drawn through a 16 gauge indwelling needle into a siliconized syringe. It has been established in our laboratory that plasma amino acid concentrations in patients with cystinuria are identical in brachial arterial and antecubital venous blood specimens. Therefore, the concentration of amino acids in antecubital venous blood can be taken to be equal to that of the renal arterial blood. Inulin concentrations in plasma and urine were measured in triplicate by the method of Schreiner (14).

Preparation of blood specimens. Blood was expressed from the siliconized syringe into a siliconized Erlenmeyer flask containing $0.1 \mathrm{mg}$ of dried sodium heparin per 10 $\mathrm{ml}$ of blood. The plasma was immediately separated by centrifugation, 15 or $20 \mathrm{ml}$ of plasma was pipetted off, and the plasma proteins were precipitated with 1 per cent picric acid (15). The picric acid was removed by the method of Stein and Moore (16). The method was modified for larger aliquots of plasma by increasing the amounts of plasma and picric acid proportionately. The final volume, after evaporation, was maintained at $10 \mathrm{ml}$ of buffered filtrate for analysis so that the peaks of the amino acids in question would be more prominent, thus facilitating measurement. Preparation of plasma in this way results in oxidation of cysteine to cystine and the subsequent chromatographic determination of both as cystine $(16,17)$. Because plasma contains both the -S-S- and -SH forms (17), and because of the unusual data obtained by the oxidation method in one case, blood and urine in one study were prepared for analysis for cystine and cysteine by the method of Brigham, Stein and Moore (17). In this method the whole blood is added to a volumetric flask containing ethylenediamine tetraacetate (EDTA) and buffered iodoacetate. The latter combines with cysteine to form S-carboxymethyl cysteine which is determined on the same resin column as cystine.

Preparation of urine specimens. Immediately after collection and measurement, an $8.0 \mathrm{ml}$ aliquot was pipetted into a $10 \mathrm{ml}$ volumetric flask and the $\mathrm{pH}$ was reduced to 3 with a few drops of $2 \mathrm{~N} \mathrm{HCl}$ (a capillary glass stirring rod was used to apply a minute amount of the solution to $\mathrm{pH}$-sensitive paper), and the specimen was brought up to volume with $\mathrm{pH} 2.2,0.2 \mathrm{~N}$ sodium citrate buffer. In the study in which blood specimens were prepared by both the oxidizing and iodoacetate methods, urine specimens were similarly treated with iodoacetate. Urine and plasma specimens thus processed were stored at $-24^{\circ} \mathrm{C}$.

Amino acid analysis. The automatic recording ionexchange column chromatographic apparatus of Spackman and associates was used (13). The $150 \mathrm{~cm}$ column was operated with $\mathrm{pH} 3.25$ buffer at $30^{\circ} \mathrm{C}$, with a change to $\mathrm{pH} 4.25$ at $50^{\circ} \mathrm{C}$ after 11 hours and $40 \mathrm{~min}$ utes. This procedure has been recommended for the determination of the acidic and neutral amino acids, including cystine, in physiological fluids (13). The 50 $\mathrm{cm}$ column with $\mathrm{pH} 4.26$ buffer throughout, with temperature change from $30^{\circ}$ to $50^{\circ} \mathrm{C}$ at 14 hours, as recommended for physiological fluids, was used for the basic amino acids (13). No attempt was made to analyze all the specimens collected for amino acids. Rather, after review of the inulin clearance data, representative periods were chosen for each range of urine flow. For each period analyzed, plasma, then urine specimens were first run on the $50 \mathrm{~cm}$ column on successive days, and then on the $150 \mathrm{~cm}$ column on successive days. In this manner, any change in "color factor" due to the slow but progressive deterioration of the stored ninhydrin reagent is kept to an incalculable minimum. The purity of the cystine, ornithine, lysine, and arginine peaks was determined in urine from two patients by splitting the effluent stream at the bottom of the columns and diverting 90 per cent of the effluent to a fraction collector (18). One-ml fractions were collected, and those corresponding to the recorded peaks for cystine, ornithine, lysine, and arginine were pooled and desalted (19). Two-dimensional paper chromatography with butanol : pyridine: $\mathrm{H}_{2} \mathrm{O}$ $(1: 1: 1)$ vs phenol: $\mathrm{NH}_{3}: \mathrm{H}_{2} \mathrm{O}(160: 0.5: 40)$ revealed single spots that were identical in position to standards (20). Peaks characteristic of pure compounds only were encountered in the present study. 
RENAL CLEARANCES IN CYSTINURIA

TABLE II

Venous plasma amino acid concentrations

\begin{tabular}{|c|c|c|c|c|c|}
\hline & \multicolumn{4}{|c|}{ Patients } & \multirow{2}{*}{$\begin{array}{l}\text { Normal } \\
\text { range }(16,17)\end{array}$} \\
\hline & M.F. & J.L. & F.C. & I.H. & \\
\hline & \multicolumn{2}{|c|}{$m g / 100 \mathrm{ml}$} & \multicolumn{2}{|c|}{$m g / 100 \mathrm{ml}$} & $m g / 100 \mathrm{ml}$ \\
\hline Cystine + cysteine & 0.32 & 0.79 & 0.79 & 0.71 & $1.08-1.30$ \\
\hline Cystine & 0.26 & & & & $0.71-0.97$ \\
\hline Cysteine & 0.09 & & & & $0.14-0.54$ \\
\hline Ornithine & 0.36 & 0.43 & 0.50 & 0.43 & $0.69-0.76$ \\
\hline Lysine & 1.56 & 2.18 & 2.36 & 1.82 & $2.51-3.02$ \\
\hline Arginine & 0.51 & 1.02 & 1.03 & 0.42 & $1.22-1.93$ \\
\hline Taurine & 1.02 & 1.53 & 2.99 & 1.22 & $0.41-0.82$ \\
\hline Aspartic acid & 0.06 & 0.10 & 0.14 & 0.08 & \\
\hline Threonine & 0.86 & 1.71 & 1.81 & 1.16 & $1.18-1.72$ \\
\hline Serine & 0.61 & 1.46 & 1.31 & 0.87 & $0.69-1.25$ \\
\hline $\left.\begin{array}{l}\text { Asparagine } \\
\text { Glutamine }\end{array}\right\}$ & 4.83 & 7.69 & 10.0 & 5.10 & \\
\hline Proline & 1.27 & 2.23 & 2.70 & 1.84 & $1.84-3.34$ \\
\hline Glutamic acid & 0.45 & 1.36 & 1.68 & 1.13 & $0.42-1.15$ \\
\hline Glycine & 1.04 & 2.00 & 1.58 & 1.35 & $1.12-1.73$ \\
\hline Alanine & 1.21 & 3.34 & 3.26 & 1.67 & $2.38-3.73$ \\
\hline$\alpha$-Amino- $n$-butyric acid & 0.19 & 0.25 & 0.29 & 0.30 & $0.18-0.35$ \\
\hline Valine & 1.44 & 1.87 & 2.69 & 1.67 & $2.24-3.71$ \\
\hline Methionine & 0.16 & 0.23 & 0.32 & 0.10 & $0.17-0.43$ \\
\hline Isoleucine & 0.56 & 0.86 & 0.98 & 0.54 & $0.69-1.28$ \\
\hline Leucine & 1.24 & 1.23 & 2.05 & 1.08 & $1.42-2.30$ \\
\hline Tyrosine & 0.60 & 0.73 & 1.06 & 0.74 & $0.81-1.45$ \\
\hline Phenylalanine & 0.57 & 0.58 & 0.93 & 0.66 & $0.69-0.95$ \\
\hline Histidine & 1.04 & 0.88 & 1.76 & 1.46 & $0.79-1.48$ \\
\hline
\end{tabular}

TABLE III

Per cent of filtered amino acid reabsorbed

\begin{tabular}{|c|c|c|c|c|c|c|c|c|c|c|}
\hline \multirow[b]{3}{*}{ Period: } & \multicolumn{9}{|c|}{ Patients } & \\
\hline & \multicolumn{4}{|c|}{ J.L. } & \multicolumn{3}{|c|}{ F.C. } & \multirow{2}{*}{$\begin{array}{c}\text { I.H. } \\
2\end{array}$} & \multicolumn{2}{|c|}{ Normal } \\
\hline & 1 & 4 & 5 & $10^{*}$ & 1 & 4 & 10 & & 1 & 5 \\
\hline Urine flow & 1.4 & 8.7 & 12.0 & 17.5 & 0.7 & 8.0 & 14.0 & 12.0 & 2.5 & 14.6 \\
\hline $\mathrm{C}_{\text {In }}$ & 75 & 116 & 105 & 111 & 154 & 137 & 123 & 83 & 128 & 128 \\
\hline Cystine + cysteine $\ddagger$ & 0 & 0 & $t$ & 17 & 26 & 18 & 0 & 16 & 99 & 100 \\
\hline Ornithinet & 41 & 50 & 47 & 55 & 69 & 68 & 63 & 68 & 100 & 100 \\
\hline Lysinef & 15 & 24 & 28 & 35 & 52 & 39 & 44 & 47 & 99 & 99 \\
\hline Arginine & 30 & 39 & $t$ & 55 & 33 & 19 & 15 & 59 & 100 & 100 \\
\hline Glycine & 96 & 96 & 96 & 96 & 99 & 98 & 97 & 94 & 97 & 97 \\
\hline Taurine & 97 & 91 & 96 & 98 & 99 & 99 & 95 & 94 & 92 & 94 \\
\hline Aspartic acid & 86 & 81 & 83 & 94 & 97 & & & 88 & 82 & \\
\hline Threonine & 98 & 99 & 98 & 98 & 99 & 99 & 99 & 99 & 99 & 99 \\
\hline Serine. & 97 & 97 & 97 & 97 & 99 & 98 & 97 & 99 & 97 & 98 \\
\hline $\left.\begin{array}{l}\text { Glutamine } \\
\text { Asparagine }\end{array}\right\}$ & 99 & 99 & 99 & 99 & 99 & 99 & 99 & 99 & 99 & 99 \\
\hline Proline & & 100 & & & & & & & 100 & 100 \\
\hline Glutamic acid & & 99 & & 99 & 100 & & & & 99 & 100 \\
\hline Alanine & 99 & 99 & 99 & 99 & 99 & 99 & 99 & & 99 & 99 \\
\hline$\alpha$-Amino- $n$-butyric acid & 99 & 96 & $t$ & 99 & 99 & & & & 99 & \\
\hline Valine & 99 & 99 & & 99 & 100 & & & & 98 & 100 \\
\hline Methionine & 98 & 99 & $\dagger$ & 92 & 99 & & & & & \\
\hline Isoleucine & 99 & 99 & $t$ & 99 & 99 & & & & 99 & 100 \\
\hline Leucine & 99 & 100 & $t$ & 100 & 100 & & 100 & & 99 & 100 \\
\hline Tyrosine & 97 & 98 & $t$ & 98 & 99 & 99 & 98 & & 98 & 99 \\
\hline Phenylalanine & 98 & 99 & $t$ & 99 & 99 & 99 & 99 & & 99 & 100 \\
\hline Histidine & 87 & 91 & 90 & 89 & 96 & 90 & 92 & 94 & 94 & 93 \\
\hline
\end{tabular}
ously.

* High flow rate was obtained in this period after administration of aminophylline and meralluride 40 minutes previ-

Complete spectrum of amino acid figures was not obtained due to technical difficulties with the apparatus.

‡ See also Tables IV and V. 
TABLE IV

Detailed data for Patient M.F.

\begin{tabular}{|c|c|c|c|c|c|}
\hline \multirow[t]{2}{*}{$\begin{array}{c}\text { Clearance } \\
\text { period }\end{array}$} & \multicolumn{2}{|c|}{$\begin{array}{l}\text { Urine } \\
\text { flow }\end{array}$} & \multicolumn{3}{|c|}{$\mathrm{C}_{\mathrm{In}}$} \\
\hline & \multicolumn{2}{|c|}{$\mathrm{ml} / \mathrm{min}$} & \multicolumn{2}{|r|}{$m l / m i n$} & \\
\hline & \multicolumn{2}{|c|}{13.7} & \multicolumn{2}{|r|}{130} & \\
\hline 2 & \multirow{2}{*}{\multicolumn{2}{|c|}{$\begin{array}{l}10.6 \\
11.4\end{array}$}} & \multirow{2}{*}{\multicolumn{3}{|c|}{$\begin{array}{l}96 \\
95.5\end{array}$}} \\
\hline \multirow[t]{3}{*}{3} & & & & & \\
\hline & \multicolumn{4}{|c|}{ Amino acid analysis for Period 3} & \multirow[b]{2}{*}{ Reab. } \\
\hline & Plasma & Filt. & Excr. & Reab. & \\
\hline & \multicolumn{2}{|c|}{ umoles/min } & \multicolumn{2}{|c|}{ umoles $/ \mathrm{min}$} & $\%$ \\
\hline \multirow{2}{*}{$\begin{array}{l}\text { Cystine + cysteine } \\
\text { Cystine }\end{array}$} & 0.026 & 2.48 & 4.20 & -1.72 & -41.0 \\
\hline & 0.022 & 2.10 & 4.20 & -2.10 & -50.0 \\
\hline & 0.004 & & & & \\
\hline \multirow{2}{*}{$\begin{array}{l}\text { Ornithine } \\
\text { Lysine }\end{array}$} & 0.05 & 4.75 & 2.27 & 2.48 & 52.2 \\
\hline & 0.13 & 12.4 & 7.72 & 4.63 & 37.3 \\
\hline Arginine & 0.05 & 4.75 & 4.54 & 0.21 & 4.42 \\
\hline Glycine & 0.31 & 29.5 & 8.06 & 21.4 & 72.7 \\
\hline Taurine & 0.05 & 4.75 & 0.09 & 4.66 & 98.1 \\
\hline Aspartic acid & 0.005 & 0.48 & 0 & 0.48 & 100 \\
\hline Threonine & 0.25 & 23.8 & 0.57 & 23.2 & 97.5 \\
\hline Serine & 0.15 & 14.3 & 0.80 & 13.5 & 94.3 \\
\hline $\begin{array}{l}\text { Glutamine } \\
\text { Asnaragine }\end{array}$ & 0.73 & 69.4 & 1.02 & 68.4 & 98.5 \\
\hline $\begin{array}{l}\text { Asparagine } \\
\text { Proline . }\end{array}$ & 0.32 & 30.4 & 0 & 30.4 & 100 \\
\hline & 0.04 & 3.80 & 0.05 & 3.72 & 97.9 \\
\hline $\begin{array}{l}\text { Alutamic acid } \\
\text { Alanine }\end{array}$ & 0.39 & 37.1 & 0.23 & 36.9 & 99.4] \\
\hline \multirow{2}{*}{$\begin{array}{l}\alpha \text {-Amino- } n \text {-butyric acid } \\
\text { Valine }\end{array}$} & 0.03 & 2.85 & 0 & 2.85 & 100 \\
\hline & 0.21 & 20.0 & 0 & 20.0 & 100 \\
\hline & 0.06 & 5.70 & 0.03 & 5.67 & 99.5 \\
\hline Leucine & 0.11 & 10.45 & 0 & 10.5 & 100 \\
\hline Tyrosine & 0.05 & 4.75 & 0.11 & 4.64 & 97.7 \\
\hline Phenylalanine & 0.04 & 3.80 & 0 & 3.80 & 100 \\
\hline Histidine & 0.08 & 7.60 & 1.02 & 6.58 & 86.6 \\
\hline
\end{tabular}

Calculations. It has been assumed in these studies that the plasma amino acids are filtered at the renal glomerulus. The validity of this assumption is based on the 100 per cent recovery of amino acids (except tryptophan) from plasma and the free ultrafiltration of plasma amino acids through cellophane membranes $(21,22)$. Thus, the concentration of amino acids in the glomerular filtrate was assumed to be the same as the concentration in plasma water. The filtered load was taken to be the product of the plasma concentration and the inulin clearance. The amount of amino acids excreted was obtained by multiplying the urinary concentration times the urine flow. The per cent reabsorbed was calculated by dividing the difference between the filtered load and the amount excreted by the filtered load.

\section{RESULTS}

Plasma concentrations. Multiple blood specimens were collected from the patients, and the concentrations of the amino acids did not vary significantly throughout the period of the study. In Table II the venous plasma amino acid concentrations from these four patients are presented.
Per cent reabsorbed. The per cent of each amino acid reabsorbed was calculated at each flow rate for each patient and in one control subject at two rates of flow. These data are summarized in Tables III and IV. In some instances data for the complete spectrum of amino acids could not be calculated because peaks of sufficient magnitude for accurate calculation were not obtained.

The data fail to indicate any clear relationship between the urinary excretion of cystine, ornithine, lysine, and arginine, and the rate of urine flow. The figures for the first clearance period on $\mathrm{Pa}$ tient J.L. may be misleading because of the apparently low inulin clearance during this period. In this patient there was not much change in renal tubular reabsorption over the flow rate 1.4 to 12.0 $\mathrm{ml}$ per minute. In the last period, a flow rate of $17.5 \mathrm{ml}$ per minute was achieved after the administration of meralluride following aminophylline. The figures for this period indicate that more of all the amino acids was reabsorbed at the high 
urine flow rate. In contrast, with Patient F.C. renal tubular reabsorption apparently decreased progressively with an increase in flow rate. However, there was a progressive fall in the inulin clearance during this study. The results on I.H. are similar to those on the other patients, with the exception that this patient seemed to reabsorb more cystine and more arginine than the others. The only exception was the instance in which meralluride was administered to J.L.

Clearance ratios. In some instances there was apparently more amino acid excreted than was filtered. The urine to plasma concentration ratio of amino acid was divided by the urine to plasma concentration ratio of inulin (clearance ratio). A ratio greater than unity suggests amino acid secretion. These data are presented in Table V.

The studies on Patient M.F. (Tables IV and V) indicate addition of cystine to the glomerular filtrate as it flows through the urinary tract. This patient was studied first, and it was felt that the results must have been erroneous. The three other patients were then studied before Patient M.F. would subnit to a repeat study. In the repeat study 7 months later similar figures were obtained (Table IV), which indicated tubular secretion of cystine. It was of great interest that there also appeared to be a tubular defect to reabsorption of glycine not seen in the other patients, and this was nearly identical in the second study. In the second study on M.F. (Table IV), the iodoacetate method was used for determination of cysteine and cystine as well as the method for oxidation and determination of both as cystine, as had been done previously. No cysteine was found in the urine, and very little in the plasma. There was a small peak for S-carboxymethylcysteine in the plasma, and calculation for cystine was slightly lower than the paired specimen prepared by oxidation (Table II).

\section{DISCUSSION}

Increased excretion of cystine, lysine, arginine, and ornithine as a result of reduced renal tubular reabsorption of these amino acids has been amply demonstrated in patients with cystinuria (2-11). It has been theorized that there is an enzymatic defect in cystinuria which results in a reduced renal tubular reabsorption of the diamino amino acids (11). There is considerable evidence that these amino acids share a common transport mechanism. Robsen and Rose (10) and Doolan, Harper, Hutchin and Alpen (7) have shown that intravenous infusion of lysine into normal subjects resulted in increased excretion of cystine and of arginine and ornithine.

In considering the renal "clearance" of cystine, several factors must be kept in mind: 1) Although both cystine and cysteine apparently exist free in the plasma, cystine with only a trace of cysteine is found in the urine (17). We infused L-cysteine into normal dogs during water diuresis. This resulted in elevation of plasma cysteine and, to a lesser extent, of cystine. However urinary cystine concentrations under this circumstance may be so high as to cause precipitation of cystine crystals. [Precipitation of cystine crystals during infusion of cysteine was also noted by Webber, Brown and Pitts (22).] The amount of cystine found, even when collected under oil and directly into iodoacetate, could not have been transferred directly from plasma by filtration, tubular secretion, or both. Therefore, this type of experiment also suggests an oxidation of the $-\mathrm{SH}$ to the $-\mathrm{S}-\mathrm{S}$ form somewhere in the nephron or urinary tract.

TABLE V

Clearance ratios of amino acid:inulin

\begin{tabular}{|c|c|c|c|c|c|c|c|c|c|c|c|c|c|}
\hline \multirow[b]{2}{*}{ Period: } & \multicolumn{2}{|c|}{ M.F. I } & \multirow{2}{*}{$\frac{\text { M.F. II }}{3}$} & \multicolumn{4}{|c|}{ J.L. } & \multicolumn{3}{|c|}{ F.C. } & \multirow{2}{*}{$\frac{\text { I.H. }}{2}$} & \multicolumn{2}{|c|}{ Normal } \\
\hline & 1 & 2 & & 1 & 4 & 5 & $10 *$ & 1 & 4 & 10 & & 2 & 5 \\
\hline Glycine & 0.22 & 0.23 & 0.28 & 0.04 & 0.04 & 0.04 & 0.04 & 0.02 & 0.02 & 0.02 & 0.03 & 0.03 & 0.03 \\
\hline $\begin{array}{l}\text { Cystine + cysteine } \\
\text { Cystine (only) }\end{array}$ & 2.4 & 2.5 & $\begin{array}{l}1.6 \\
2.0\end{array}$ & 1.0 & 1.0 & & 0.90 & 0.79 & 0.82 & 1.1 & 0.85 & 0.004 & \\
\hline Ornithine & & 0.67 & 0.51 & 0.58 & 0.56 & 0.54 & 0.45 & 0.33 & 0.33 & 0.38 & 0.33 & & \\
\hline Lysine & & 0.79 & 0.61 & 0.85 & 0.77 & 0.71 & 0.65 & 0.51 & 0.63 & 0.56 & 0.53 & 0.003 & \\
\hline Arginine & & 1.39 & 1.0 & 0.70 & 0.57 & & 0.46 & 0.71 & 0.83 & 0.85 & 0.42 & & \\
\hline
\end{tabular}

* After aminophylline and meralluride. 
Some other mechanism may be possible, of course, since such an oxidation has not been proven. However, an oxidation reaction seems most likely on the basis of currently available data. The low plasma values for both cysteine and cystine in cystinuria are compatible with this concept. 2) Neither the intratubular concentrations of the reduced and oxidized form nor the details of transport across the tubular cell are known. Hence, it is necessary to consider cystine and cysteine together. 3) The occurrence of the mixed disulfide of L-cysteine and L-homocysteine in the urine of patients with cystinuria has been established in this laboratory (12). ${ }^{1}$ Significant amounts of this compound have been found in the urine, although its origin has not been determined. It is not known whether previous investigators measured this compound as cystine or not at all. It has been found in our laboratory that the compound is unstable in alkaline solutions, particularly under conditions that favor oxidation, and appears to break down to yield cystine and homocystine, apparently through disulfide interchange. Dent, Senior and Walshe noted that column chromatography gave consistently lower values than did polarographic determinations for cystine on the same specimens of urine (9). It is possible that some plasma cysteine enters into the formation of the mixed disulfide, and this may further complicate the issue. In spite of the difficulty imposed by the problem of cystine measurement and consideration of a "cystine clearance," certain statements can be made.

Plasma amino acid concentrations. The finding of low plasma concentrations of cystine, ornithine, lysine, and arginine confirms the reports of others (5-8). Also, in one patient (M.F.) the low concentration of cysteine, noted by Brigham, Stein and Moore (17), is confirmed. The somewhat low plasma glycine in Patient M.F. is of interest in regard to the elevated clearance (decreased reabsorption) of this amino acid (see below). The plasma cystine of Patient M.F. is the lowest of the four patients, and must be considered in relation to the apparent high clearance of cystine in this patient. A similarly low value of $0.30 \mathrm{ml}$ per

1 At the time the abstract on this work was submitted, there was evidence that this compound was peptide in nature (1). However, since then, positive identification has been established (12).
$100 \mathrm{ml}$ was found in one other patient, not included in this study, whose urine to plasma concentration ratios were considered meaningless because he was passing cystine gravel.

There are other occasional values in the plasma of these patients that are beyond the normal range. This "normal range" is taken from the data of Stein and Moore with five subjects and the data of Brigham and co-workers on five subjects (cysteine, cystine, and cysteine plus cystine only in one of these last five) $(16,17)$. It has been our experience that plasma specimens frequently show deviation beyond this "normal range." Taurine levels in plasma from "normal" subjects in our laboratory have ranged from 0.45 to $3.47 \mathrm{ml}$ per $100 \mathrm{ml}$. (Plasma taurine concentrations in various disease states have varied inconsistently in our laboratory.) There is some precedent for this finding in the literature-Brigham and associates reported plasma taurine levels of 0.67 and $1.50 \mathrm{mg}$ per $100 \mathrm{ml}$ in two patients with Fanconi syndrome (17). The four patients with cystinuria, who form the basis for the present paper, all had plasma taurine levels higher than the "normal range."

Arrow and Westall, who used ion-exchange chromatography, listed a plasma taurine concentration range of 0.4 to $1.87 \mathrm{mg}$ per $100 \mathrm{ml}$, but the data are grouped under "other amino acids" and it is not possible to distinguish plasmas from patients with cystinuria from normal plasmas (8). The significance of the plasma taurine levels found in the present study is unknown.

Some of the other plasma amino acid levels appear to be outside the "normal range." $\mathrm{Pa}$ tients M.F., J.L., and I.H. tend to have occasionally low values. These patients had been maintained for several months on a low methionine, and therefore, a low protein diet. It seems possible that this accounts for the low concentrations. However, detailed study of the long-term effects of a low protein diet on individual plasma free amino acid concentrations has not been published.

Amino acids reabsorbed. In the normal subject, there was 97 to 100 per cent reabsorption of most amino acids. The data in Tables III and IV clearly indicate that in cystinuria there is considerably less reabsorption of cystine, ornithine, lysine, and arginine. These observations, in general, confirm the observations of previous investi- 
gators (7-11). In the two patients in whom urinary flow was gradually increased, there was no consistent change in renal tubular reabsorption of these amino acids. In one patient reabsorption of amino acids tended to increase with flow; in another patient, reabsorption tended to decrease with increasing flow. It is difficult to predict the effect of the organic mercurial on cystinuria in view of its known ability to bind sulfhydryl groups. However, the trend toward increased reabsorption with increased flow continued.

Amino acid-inulin clearance ratios. Patient M.F. was clearly unique in that the clearance ratio of cystine to inulin (Table V) was consistently greater than 1.0, indicating addition of this amino acid to that filtered at the glomeruli. An obvious cause for this type of result would be calculus dissolution. However, this patient was scrutinized very carefully by repeated urinalyses and by intravenous pyelography, and no evidence for calculi was found. Furthermore, this patient had a high clearance ratio for arginine, which was 1.3 on the first study and 1.0 on the second. Her clearance ratios for ornithine and lysine were always high, although not consistently higher than those of some of the other patients. In addition, the persistent reabsorptive defect to glycine would tend to confirm the fact that the manifestations of the disease were somewhat different in this patient. When the method of Brigham and co-workers (17) was used to bind plasma cysteine in the second study, the clearance ratio was 2.0 for cystine alone, and 1.6 when plasma cystine and cysteine were determined as cystine. The complete data for the second inulin-amino acid clearance study for this patient are presented in Table IV. This patient had good renal function as determined by phenolsulfonthalein excretion, urea clearance, and inulin clearance. Studies of concentrating ability were not attempted because of the danger of calculus formation. However, it is conceivable that repeated attacks of renal colic, usually due to ureteral calculi and possibly accompanied by infection, and operative removal of calculi on three occasions in the past had aggravated the inability to reabsorb amino acids properly. The selection of glycine alone, however, in addition to the 4 diamino amino acids makes this a somewhat unlikely explanation. Equally unlikely is the possibility that she has two disorders, a defect to glycine reabsorption accompanied by tubular secretion of cystine, in addition to the classical cystinuria.

Webber and associates noted that infusion of lysine, arginine, ornithine, cysteine, and histidine into normal dogs resulted in a decrease in the reabsorption of glycine of the same order noted in Patient M.F. (22). This suggests that the glycine abnormality may be related to the amino acid transport defect of cystinuria in some manner, or that it is secondary to the high renal tubular luminal or renal tubular cell concentrations of the basic amino acids.

Webber and colleagues also noted apparent amino acid secretion on occasion in their experiments, and considered possible mechanisms of this phenomenon (22). One of these would be that there is normally bidirectional movement of amino acids across the tubular cell. Secretion might be detected if reabsorption were defective. Another possibility proposed by these authors is that there might be a linked exchange of the "highly concentrated amino acid in the tubular fluid for another amino acid within the cells" (22).

Still another possibility, at least in the case of cystine, is that the substance might be formed in part in the tubular cells. Thus, the amino-aciduria might be a reflection of a metabolic abnormality within the renal tubular cell quite apart from the transport defect. This is suggested by the fact that plasma cysteine is apparently excreted as cystine, and also by our finding of the disulfide of cysteine and homocysteine in the urine of patients with cystinuria.

The origin of this amino acid, which to date has been found only in the urine of patients with cystinuria, is not presently known. It seems unlikely that it is formed simply because of the high concentrations of cystine (and perhaps cysteine) in the tubular fluid. When cysteine was infused into a normal dog, large amounts of cysteine and cystine appeared in the urine. However, the mixed disulfide was not present. Whether the mixed disulfide is formed outside of the kidney cannot be definitely stated. Although it has not been identified in the plasma of patients with cystinuria, it may be present in quantities not detectable by current methods. Thus, it is possible that the urinary cystine in cystinuria is in part secondary to some metabolic defect within the renal tubular 
cell, and the high excretions of the basic amino acids may be directly related in some unknown way. However, the augmented excretion of these basic amino acids may be secondary to the large luminal concentrations of cystine.

\section{SUMMARY AND CONCLUSIONS}

1. Simultaneous inulin and endogenous amino acid renal clearances were studied in four patients with classical cystinuria. Although the reabsorption of basic amino acids was abnormal in all, there was considerable variability between patients in the fraction of filtered cystine, arginine, lysine, and ornithine reabsorbed. In general, the reabsorptive defect was greatest for cystine, somewhat less for lysine and arginine, and least for ornithine. In this respect, the results were similar to the reports of previous workers.

2. Increasing urine flow during the inulin clearance in two patients had an inconstant effect of relatively small magnitude.

3. In one patient, apparent tubular secretion of cystine was seen on repeated examinations, as well as possible tubular secretion of arginine. This patient also had a renal tubular reabsorptive defect for glycine. The data are interpreted as suggesting that cystinuria may represent a complex metabolic abnormality of the renal tubule, rather than a simple block of tubular reabsorption.

\section{ACKNOWLEDGMENT}

We wish to acknowledge the assistance of Miss Doris Ibsen, Chief Nurse, and her staff of the metabolic ward, and of Miss Margaret O'Hara, Research Dietitian, in the conduct of these studies. We are indebted to the urology staff of the New York Hospital for their referral and assistance in the evaluation and management of these patients.

\section{REFERENCES}

1. Frimpter, G. W., Bass, A., Furth, E., Horwith, M., and Thompson, D. D. Cystinuria: Amino acid clearances and the occurrence of a cystine peptide (abstract). J. clin. Invest. 1961, 40, 1040.

2. Wollaston, W. H. On cystic oxide, a new species of urinary calculus. Phil. Trans. B 1810, 100, 223.

3. Yeh, H. L., Frankl, W., Dunn, M. S., Parker, P., Hughes, B., and György, P. The urinary excretion of amino acids by a cystinuric subject. Amer. J. med. Sci. 1947, 214, 507.
4. Stein, W. H. Excretion of amino acids in cystinuria. Proc. Soc. exp. Biol. (N. Y.) 1951, 78, 705.

5. Brown, B. H., and Lewis, H. B. Cystine in normal and cystinuric human blood. Proc. Soc. exp. Biol. (N. Y.) 1937, 36, 487.

6. Fowler, D. I., Harris, H., and Warren, F. L. Plasmacystine levels in cystinuria. Lancet 1952, 1, 544.

7. Doolan, P. D., Harper, H. A., Hutchin, M. E., and Alpen, E. L. Renal clearance of lysine in cystinuria; pathogenesis and management of this abnormality. Amer. J. Med. 1957, 23, 416.

8. Arrow, V. K., and Westall, R. G. Amino acid clearances in cystinuria. J. Physiol. (Lond.) 1958, 142, 141.

9. Dent, C. E., Senior, B., and Walshe, J. M. The pathogenesis of cystinuria. II. Polarographic studies of the metabolism of sulphur-containing aminoacids. J. clin. Invest. 1954, 33, 1216.

10. Robson, E. B., and Rose, G. A. The effect of intravenous lysine on the renal clearances of cystine, arginine and ornithine in normal subjects, in patients with cystinuria and Fanconi syndrome and in their relatives. Clin. Sci. 1957, 16, 75.

11. Dent, C. E., and Rose, G. A. Aminoacid metabolism in cystinuria. Quart. J. Med. 1951, 20, 205.

12. Frimpter, G. W. The disulfide of L-cysteine and L-homocysteine in urine of patients with cystinuria. J. biol. Chem. 236, PC 51, 1961.

13. Spackman, D. H., Stein, W. H., and Moore, S. Automatic recording apparatus for use in the chromatography of amino acids. Analyt. Chem. 1958, 30, 1190.

14. Schreiner, G. E. Determination of inulin by means of resorcinol. Proc. Soc. exp. biol. (N. Y.) 1950, $74,117$.

15. Hamilton, P. B., and Van Slyke, D. D. The gasometric determination of free amino acids in blood filtrates by the ninhydrin-carbon dioxide method. J. biol. Chem. 1943, 150, 231.

16. Stein, W. H., and Moore, S. The free amino acids of human blood plasma. J. biol. Chem. 1954, 211, 915.

17. Brigham, M. P., Stein, W. H., and Moore, S. The concentrations of cysteine and cystine in human blood plasma. J. clin. Invest. 1960, 39, 1633.

18. Woods, K. R., and Engle, R. L., Jr. Automatic analysis of amino acids. Ann. N. Y. Acad. Sci. 1960, 87, 764.

19. Thompson, J. F., Morris, C. J., and Gering, R. K. Purification of plant amino acids for paper chromatography. Analyt. Chem. 1959, 31, 1028.

20. Smith, I. Chromatographic Techniques. London, Heinemann, 1958.

21. McMenamy, R. H., Lund, C. C., and Oncley, J. L. Unbound amino acid concentrations in human blood plasmas. J. clin. Invest. 1957, 36, 1672.

22. Webber, W. A., Brown, J. L., and Pitts, R. F. Interactions of amino acids in renal tubular transport. Amer. J. Physiol. 1961, 200, 380. 